\title{
Study of the Behavior of Water Droplets Under the Influence of a Uniform Electric Field on Conventional Polyethylene and on Crosslinked Polyethylene (XLPE) with MgO Nanoparticles Samples
}

\author{
C. Charalambous \\ Democritus University of Thrace, \\ Department of Electrical \& Computer \\ Engineering, Power Systems Laboratory, \\ Greece \\ crcharal@ee.duth.gr

\section{N. Vordos} \\ Hephaestus Advanced Laboratory, \\ Eastern Macedonia and Thrace Institute \\ of Technology, Greece \\ vordosn@yahoo.com
}

\author{
M. G. Danikas \\ Democritus University of Thrace, \\ Department of Electrical \& Computer \\ Engineering, Power Systems Laboratory, \\ Greece \\ mdanikas@ee.duth.gr
}

\author{
J. W. Nolan \\ Hephaestus Advanced Laboratory, \\ Eastern Macedonia and Thrace Institute \\ of Technology, Greece \\ jnolan@teikav.edu.gr
}

\author{
Y. Yin \\ Shanghai Jiao Tong University, State \\ Energy Smart Grid R\&D Research \\ Center, Shanghai, People's Republic of \\ China \\ yiny@sjtu.edu.cn
}

\author{
A. Mitropoulos \\ Hephaestus Advanced Laboratory, \\ Eastern Macedonia and Thrace Institute \\ of Technology, Greece \\ amitropoulos@teikav.edu.gr
}

\begin{abstract}
It is well known that polyethylene (PE) and crosslinked polyethylene (XLPE) are suitable insulating materials for underground cables. Samples of PE and of XLPE with MgO nanoparticles were investigated regarding their flashover behaviour with a uniform electric field and water droplets of various conductivities. In the present paper, the effect of the mounting arrangement of the water drops on the value of the flashover voltage and the effect of the volume of dripping water on the flashover voltage were also studied. Surface damages were analyzed using Scanning Electron Microscopy (SEM) studies and the study of the nano-structure of the samples was studied using the SAXS system.
\end{abstract}

Keywords-polyethylene; cross-linked polyethylene; flashover; surface discharges; polymer nanocomposites

\section{INTRODUCTION}

The insulating materials used for equipment of high voltages during operation for many years, are stressed by various factors. An important factor that contributes to the aging of the insulation is moisture, which in combination with the electrical stress causes changes in the condition of the insulating surface. These changes on the surface can cause the onset of partial discharges and eventually the gradual disintegration of the insulating material. In this paper, a comparison is made of the two types of insulation materials, i.e. between a conventional polymer material $(\mathrm{PE})$ and a polymer nanocomposite material (XLPE with $\mathrm{MgO}$ nanoparticles. It is an experimental study using samples of PE and samples of XLPE with nanoparticles of magnesium oxide $(\mathrm{MgO})[1,2]$.

The purpose of the present work was to answer the question whether the addition of nanoparticles to a polymer insulator improves or not the flashover voltage. In the present study, the behavior of the said samples of insulating material with drops of water placed on the surface of samples of different conductivity from $0.8 \mu \mathrm{S} / \mathrm{cm}$ to $10000 \mu \mathrm{S} / \mathrm{cm}$, under the effect of a uniform electric field. Apart from the experimental measurements of water drops of different conductivities, some diagnostics are also reported regarding the results of surface erosion with the Small Angle X-Ray Scattering (SAXS) technique and with a Scanning Electron Microscope (SEM).

\section{EXPERIMENTAL STUDIES}

For the production of high voltage for carrying out the experiments, a high voltage power supply comprising a voltage transformer with dry insulation (epoxy resin) with a rated voltage of $20 \mathrm{kV}$. Thus by controlling the voltage of the secondary winding through the autotransformer have the other side of the transformer voltages from $0 \mathrm{~V}$ to $28 \mathrm{kV}$. For the 
experiments two hollow electrodes were made of copper. The electrodes were bonded to the high voltage terminals of the feeder, and the distance between the two electrodes during the experimental measurements were constant at $2.5 \mathrm{~cm}$. The dimensions of the electrodes are shown in Figure 1.

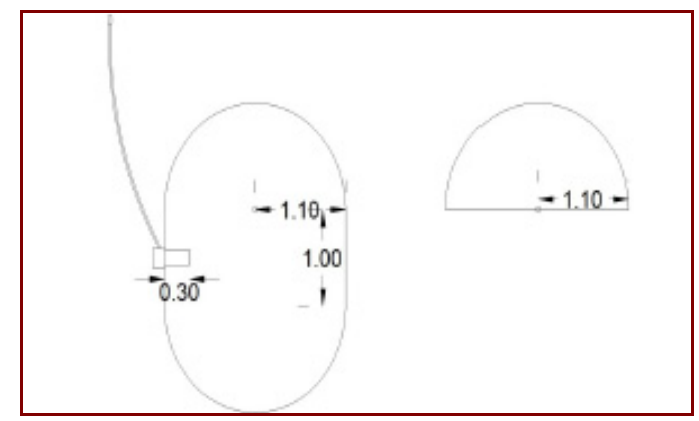

Fig. 1. Top view and transverse electrode section.

The water droplets were positioned on the polymeric material surface with the aid of a special arrangement consisting of a metallic frame and three rules, one of which had two laser indicators. The water droplets were put on the surface with a $10 \mathrm{ml}$ syringe. Detailed information on the way the droplets were positioned on the polymeric surface is given in Figure 2. The insulation materials investigated during the experiments were both conventional PE and XLPE with MgO nanoparticles (having $0.5 \mathrm{wt} \%$ nanoparticles). The water samples that were used for the experiments were eight, namely with conductivities of $0.8 \mu \mathrm{S} / \mathrm{cm}, 100 \mu \mathrm{S} / \mathrm{cm}, 200 \mu \mathrm{S} / \mathrm{cm}, 500$ $\mu \mathrm{S} / \mathrm{cm}, 1000 \mu \mathrm{S} / \mathrm{cm}, 2000 \mu \mathrm{S} / \mathrm{cm}, 5000 \mu \mathrm{S} / \mathrm{cm}$ and 10000 $\mu \mathrm{S} / \mathrm{cm}$. The apparatus used for measuring the conductivity was an electronic conductivity meter brand WTW inoLab cond Level 1 electrode (Probe) WTW Tetracon 325.

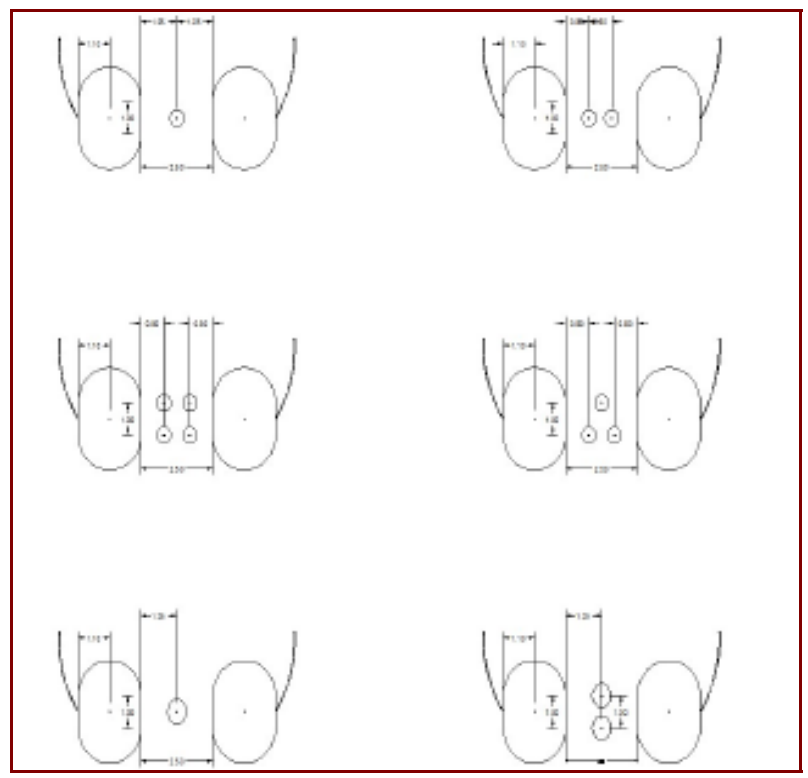

Fig. 2. Water droplet arrangements between the electrodes.

The arrangements shown in Figure 2 implemented with both water drops of $0.05 \mathrm{ml}$ and water drops of $0.1 \mathrm{ml}$. Also measurements were made on arrangement of a droplet volume of $0.2 \mathrm{ml}$ and $0.3 \mathrm{ml}$. After completion of the measurements with the water drops on the surface of the samples, the surface erosion was investigated by means of a SAXS system (Small Angle X-Ray Scattering) and an Scanning Electron Microscope (SEM).

\section{EXPERIMENTAL METHODOLOGY}

To perform the experiments followed the following procedure: Once placed, the specified volume of water drops and conductivity on the insulating material in one of the aforementioned arrangements, the output voltage of the power supply was gradually increased until the flashover of the gap and recording of the breakdown voltage. After cleaning the insulating surface with alcohol, we repeated the same procedure by increasing the voltage of the power supply until the last recorded value reduced by $1.2 \mathrm{kV}$ in order not to bring about the flashover of the gap. At this point we leave the output voltage of the power supply steady for five minutes to provide the necessary time for the process of deformation of the drop to be developed, the occurrence of partial discharges and ultimately overcome or not the gap. If there was not arcing and/or flashover, the voltage was increased at $0.4 \mathrm{kV}$ steps until the occurrence of a flashover. This was the value of breakdown voltage that was finally recorded.

Variable parameters during the experiments were as follows:

- The arrangement of water drops

- The conductivity of the dripping water

- The volume of water drops

- The kind of the insulating material

- The distance of the drops from the electrodes

\section{A. Effect of water drops to the breakdown of insulating materials}

During operation the insulating materials are stressed by various environmental factors. One of the major factors of aging is moisture, which in combination with the electrical stress may cause changes on the surface of insulation. Polymer insulation materials are widely used in high voltage applications. They are, however, sensitive to, among other factors, partial discharges. Upon exposure of the polymer to rain or moisture, water droplets are formed on the surface of the insulation and hence the conductive contamination on the surface of insulation may follow. Water droplets on the surface of a polymer material can cause -with an electric field presentdegradation of insulation even in low pollution conditions. This is due to the fact that water droplets on a polymer surface locally increase the applied electric field. An excessive increase in the localized electric field may result in certain local discharges and/ or arcs, which in turn make it possible to create the dry strips on the polymer surface. Bridging of individual dry bands through the local electric arcs will eventually lead to a complete flashover [3]. This discharge mechanism can occur in both indoor insulations and outdoor insulations although 
each of these categories has its own peculiarities. Generally, a combination of water droplets and dust as impurities on the surface of an insulating surface can lead to contamination, which may in turn result in significant reduction in flashover voltage. As shown in previous studies [4-7], the conductivity of the droplets, the roughness of the polymer surface, the volume of the droplets and the arrangement of the droplets in relation to the electrodes affect their behavior.

\section{B. Forces applied on a drop of water on the polymer surface}

Figure 3 shows the forces exerted on the droplet in case there is no applied electric field [4]. Such forces are the surface tension of the liquid $\left(\tau_{\mathrm{L}}\right)$, the surface tension of the solid $\left(\tau_{\mathrm{S}}\right)$ and the interfacial tension between the liquid and solid $\left(\delta_{\mathrm{SL}}\right)$. When an electric field is applied, the droplet is deformed due to an additional force applied to it. The tangential electric field on the insulation surface creates a force on the surface of the droplet causing deformation. The deformation of droplets adversely affects the uniform distribution of the electric field. Droplet deformation could cause local increases in the electric field which in turn will cause local micro-discharges between the droplets. This is the beginning of the electrochemical deterioration of the insulation surface. Hydrophobicity can be locally lost [8-10]. Reduced hydrophobicity implies a higher risk of discharge [10]. Solvable nitrates - the result of electrochemical deterioration - will cause a higher conductivity of the water droplets. Dry zones may ensue. Around the water droplets the electric field will be modified. The point where the electric field gets the highest value is the triple point. As was pointed out elsewhere [11], it is important to bear in mind that not only the influence of the applied electric field on the shape of the droplet is of great significance, but also the influence of the disintegrated droplet on the electric field distribution. Micro-discharges, which eventually will develop into full partial discharges are among the major causes of insulation aging [12].

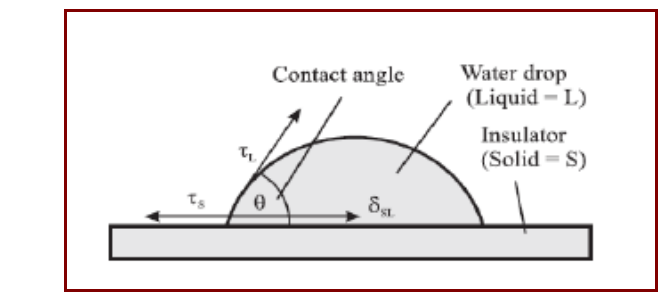

Fig. 3. Forces applied to a water drop on insulating surface.

\section{SEM AND SAXS ANALYSIS}

The PE and XLPE were studied with a JEOL JSM 6390LV Scanning Electron Microscopy (SEM), in high vacuum mode at $20 \mathrm{kV}$. Before introduction to the SEM for imaging, samples were coated with a thin layer of gold to reduce sample charging. Ten images were selected from different areas on each surface. Small Angle X - Ray Scattering was performed in a SAXS rig system provided by JJ X - Ray Systems, with a $\mathrm{CuKa} x$ ray source $(\lambda=0.15056 \mathrm{~nm})$. The apparatus consists of the 2D Rigaku SMAX -300 detector, vacuum chamber, pinholes to collimate the beam, and an X-ray source. Each sample was measured at $2.5 \mathrm{~m}$ (detector-to-sample distance for $3600 \mathrm{sec}$ exposure time). The background radiation and the matrix spectra were recorded for the same time period. Silver Behanate was used to calibrate the center and the $\mathrm{Q}$ range of the detector. All measurements were corrected for background radiation, and transmission.

\section{RESULTS AND DISCUSSION}

From Figures 4 and 5, it is evident that the droplet volume plays a significant role in determining the flashover voltage in PE.. Moreover, from Figure 4 is indicated that the positioning of droplets influences the flashover voltage (if we compare the data of the 2 droplets put horizontally and of the 2 droplets put vertically on the sample). The droplet volume effect is even more dramatic in Figure 5. Needless to remark that it is obvious that the water conductivity affects greatly the droplet behavior and the flashover voltage. It is observed that the conductivity of the drops solution plays an important role in flashover voltage. The greater the conductivity of the water drops the smaller the value of the flashover voltage.

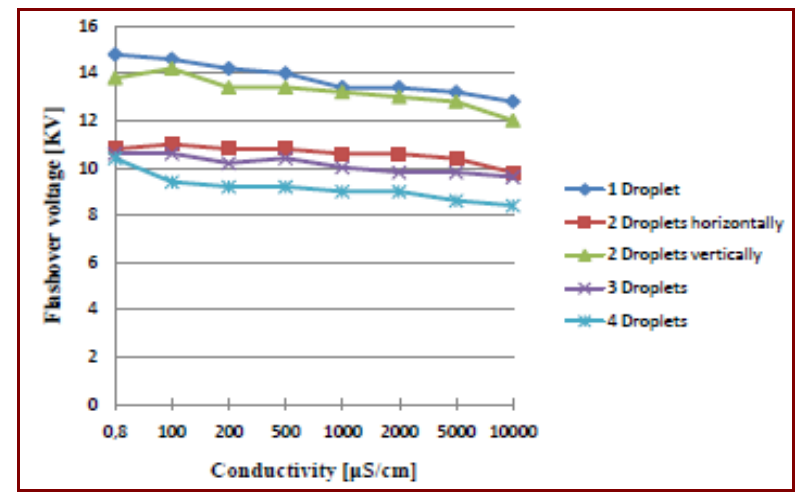

Fig. 4. Flashover voltage for pure polyethylene sample with $0.05 \mathrm{ml}$ volume droplets.

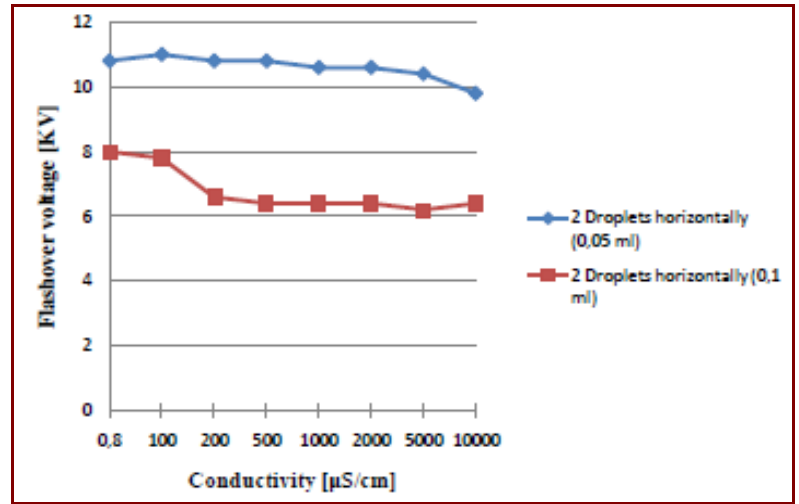

Fig. 5. Comparison of results for two drops assembly horizontally volume $0.05 \mathrm{ml}$ and $0.1 \mathrm{ml}$ in pure polyethylene sample.

Figures 6 and 7 show the results for XLPE with $0.5 \mathrm{wt} \%$ nanoparticles of $\mathrm{MgO}$. Here again one may see the effect of water droplet conductivity on the flashover voltage as well the effect of droplet volume. For both materials (PE and the nanocomposite), it is evident that the distance of the droplets 
from the electrodes plays a role and it was noted that the nearer the droplets to the electrodes, the lower the flashover voltage. This phenomenon was noticed before with other insulating materials [5-7, 11]. In Figures 8 and 9, a direct comparison between the two materials is made. It is clear that the nanocomposite XLPE (with $0.5 \mathrm{wt} \% \mathrm{MgO}$ nanoparticles) tends to give higher flashover results than the conventional PE. This is a strong indication that nanoparticle addition improves the flashover voltage. This may be due to the gradual erosion of the surface and the emerging onto the surface of the nanoparticles, which in turn hinder the propagation of surface discharges. This explanation seems plausible and was given in $[13,14]$.

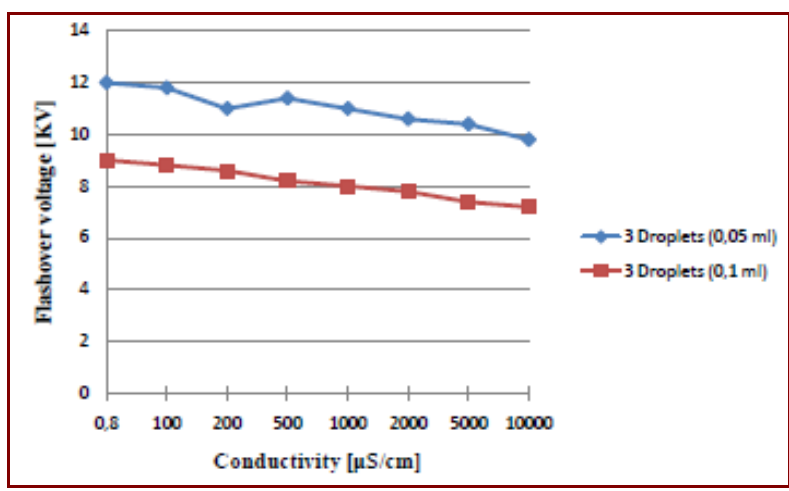

Fig. 6. Flashover voltages for XLPE- $\mathrm{MgO}$ sample with $0.05 \mathrm{ml}$ volume droplets.

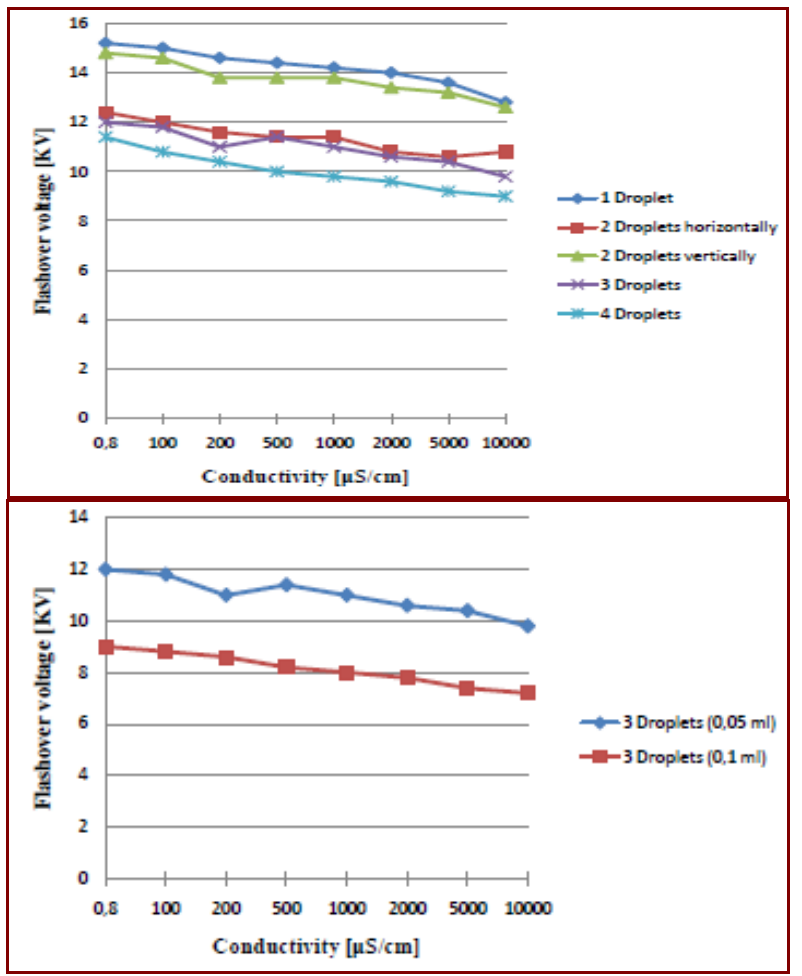

Fig. 7. Comparison of results for three drops on triangle arrangement with volume $0.05 \mathrm{ml}$ and $0.1 \mathrm{ml}$ on XLPE- MgO sample.
It seems that the addition of nanoparticles is beneficial for the flashover voltage. The addition of nanoparticle percentage depends on the polymer matrix as well on the type of the added nanoparticles. Nevertheless, according to the literature, there is an optimum nanoparticle addition rate above which the properties of the insulating material deteriorate. This phenomenon is attributed to the formed nanoparticle aggregates within the polymer matrix which act negatively on the performance of the insulating material $[15,16]$. In addition to experimental measurements made in the high-voltage laboratory for the study of the flashover voltage, the surface of the insulating materials tested was studied by using some well known diagnostic methods. These experiments relating to Small Angle X-ray Scattering (SAXS), and the study of samples of insulating material with a Scanning Electron Microscope (SEM). Small Angle X - Ray Scattering (SAXS) is an analytical method for the determination of particle size and shapes in the nanoscale. Typically, the SAXS curves are divided in five regions (Guinier, Fractal, Porod, Micropore Shoulder and near beam region). Due to the nature of the sample, the SAXS curves may have less than the 5 regions. According to Guinier, the radius of gyration $\mathrm{Rg}$, can be calculated from the Guinier plot (I(q) vs q2). $\mathrm{Rg}$ is an indicator of how the mass of a particle is distributed around its center of mass [17].

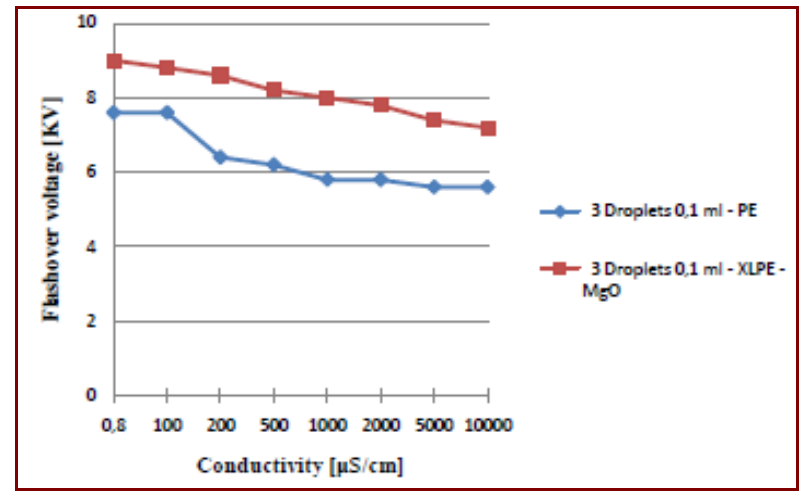

Fig. 8. Comparison of the two insulating materials for three drops on triangle arrangement with volume $0.1 \mathrm{ml}$.

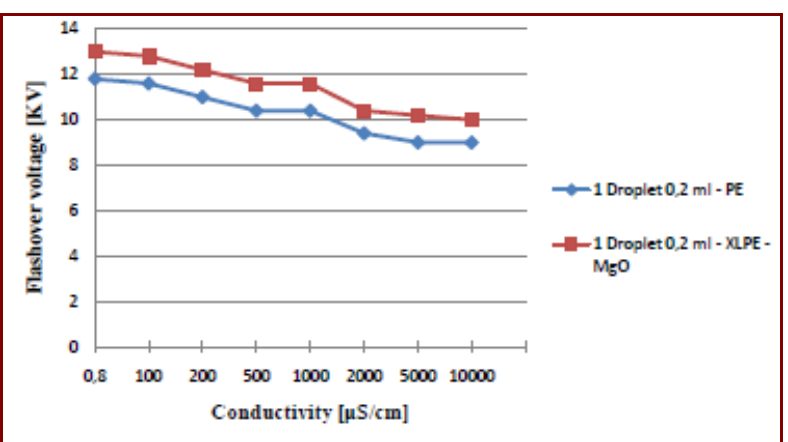

Fig. 9. Comparison of the insulating materials for arrangement of a drop with volume $0.2 \mathrm{ml}$.

Figures 10 and 11 illustrate a graphical comparison of curves derived from the study of the polyethylene before and 
after the discharge (Figure 10) and the XLPE with $\mathrm{MgO}$ nanoparticles (Figure 11). In Figure 10, the blue line shows the curve corresponding to the case of the material after the discharge, while curve in red corresponds to the case of the material that has not suffered a flashover, whereas in Figure 11 the red line indicates the material that suffered flashover. In Figures 10 and 11, we observe that more distortion occurs in the structure of the crosslinked polyethylene (XLPE) with $\mathrm{MgO}$ nanoparticles, but as shown in Figure 11, the structure is somewhat more compact after discharge. As indicated in the studies $[13,14]$, this can be attributed to the fact that during the discharge the polymer matrix material decomposes and nanoparticles creating agglomerates gather near the surface. This makes the material more compact.

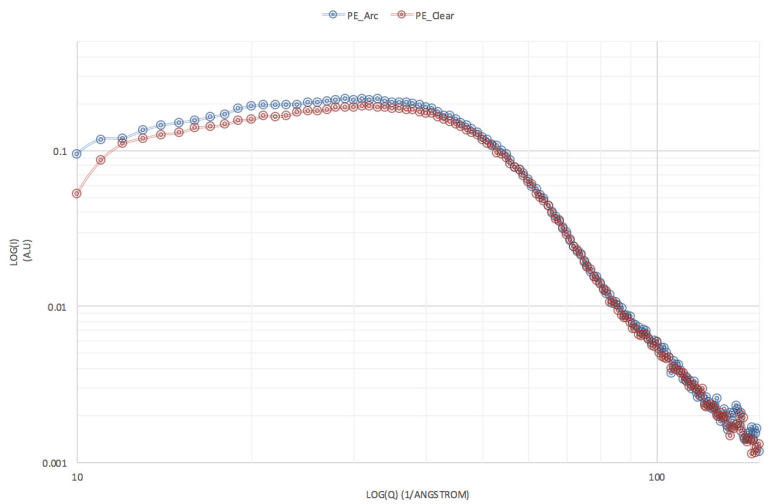

Fig. 10. Comparison of two samples PE.

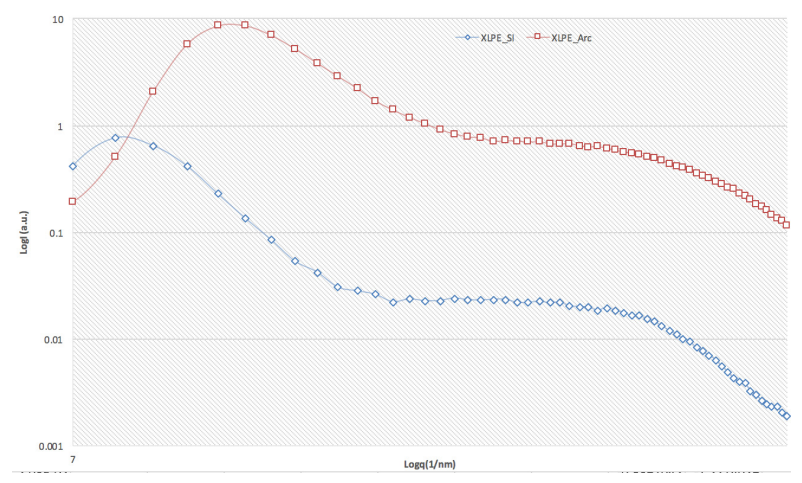

Fig. 11. Comparison of two samples XLPE.

From the electron density differences of the XLPE and PE samples the periodicity of the samples can be measured. The periodicity interprets the characteristic spacing of crystalline and non - crystalline domains for a two - phase system and represented as $L_{p}$ and called long period. The long period determined and $\mathrm{L}_{\mathrm{p}}=2 \pi / \mathrm{q}_{\max }$ is the peak position of $\mathrm{I}(\mathrm{q})$ versus $\mathrm{q}$ plot [18]. The long period for the PE sample before and after discharge is $14.8 \mathrm{~nm}$. The XLPE long periods before and after discharge are $13 \mathrm{~nm}$ and $48 \mathrm{~nm}$ respectively. The increasing of crystallinity can be explained as an increasing of nanoparticles agglomerates due to destroying of the XLPE nanostructure. Another diagnostic method used is the Scanning Electron Microscopy (SEM). Electronic Scanning Microscopy is one of the modern and flexible methods of analysis of the microstructure of a large number of materials.

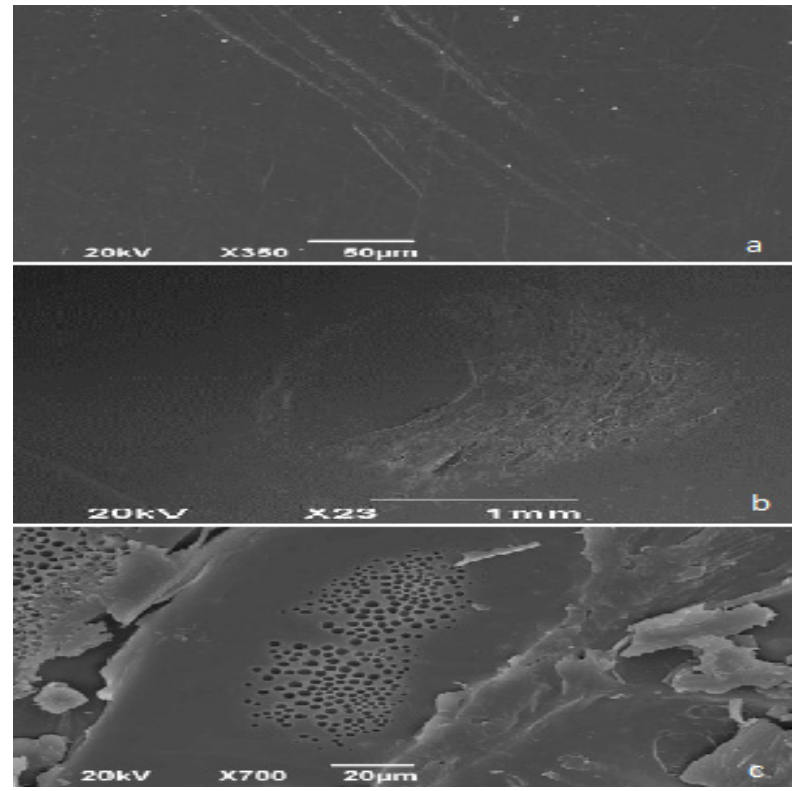

Fig. 12. SEM micrographs of the polyethylene insulation surface: (a) Virgin (b) Damaged by arc (c) Magnification of damaged area.

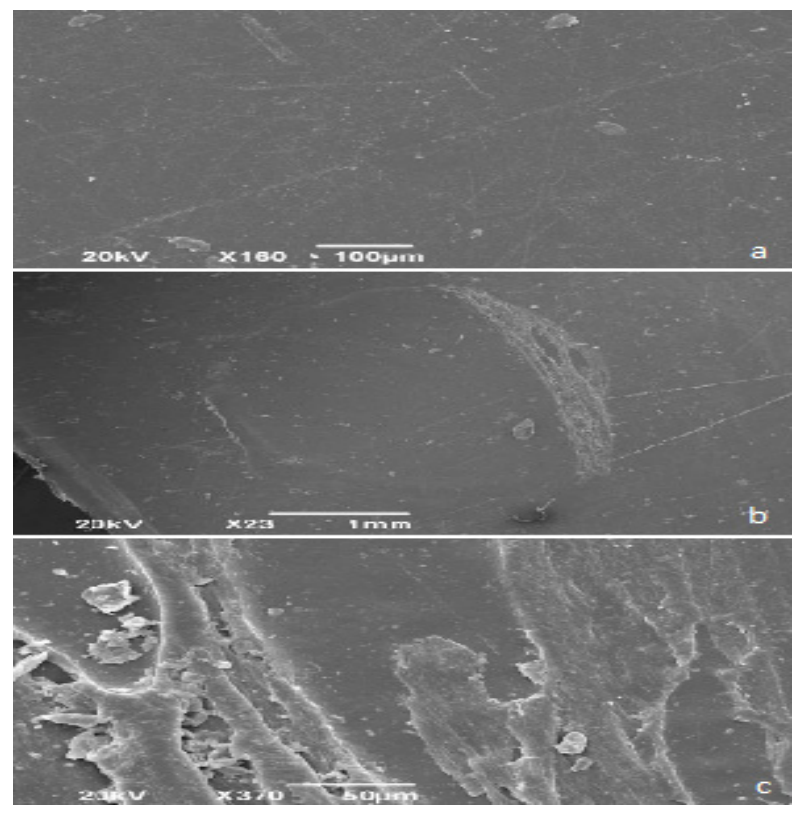

Fig. 13. SEM micrographs of the XLPE - MgO insulation surface: (a) Virgin (b) Damaged by arc (c) Magnification of damaged area.

Figure 12 shows SEM micrographs of the polyethylene insulation surface. Figure 12(a) shows the surface before the discharge, Figure 12(b) shows the damage of the surface caused by arc after the discharge and Figure 12(c) shows a magnification of the damaged area. Figure 13 shows SEM micrographs of the XLPE-MgO insulation surface. Figure 13(a) shows the surface before the discharge, Figure 13(b) shows the damage of the surface caused by arc after the 
discharge and finally Figure 13(c) shows a magnification of the damaged area. From the images obtained with the scanning electron microscope can be seen that in the case of the polyethylene sample, in contrast to the case of XLPE, in regions where they had undergone damage, the formation of pinholes in the surface of the insulating material was observed (Figure 12 (c)). It is evident that XLPE with $\mathrm{MgO}$ nanoparticles behaves better that conventional PE. This generally agrees with previously published work, namely that small percentage additions of nanoparticles improve the electrical properties of conventional polymers [19-21].

\section{CONCLUSIONS}

According to the results of the experiments, it is clear that by increasing the water conductivity, the value of the flashover voltage decreases. Also an important role in the flashover voltage play the water droplets arrangement. The more droplets were, the smaller was the value of the flashover voltage. Finally, from the results of the experimental measurements it is observed that by increasing the volume of water droplets, the flashover voltage decreases. As shown by the experiments made by SAXS system, the largest alteration occurs in the structure of the crosslinked polyethylene (XLPE) with $\mathrm{MgO}$ nanoparticles, but it is observed that the structure becomes somewhat more compact after discharge. The Scanning Electron Microscope indicated that in the case of the conventional polyethylene - in contradistinction to the case of XLPE with MgO nanoparticles - small holes have been observed, which may be the cause of further surface discharges. As a final conclusion, it can be suggested that the crosslinked polyethylene (XLPE) with addition of $0.5 \mathrm{wt} \%$ nanoparticles of magnesium oxide ( $\mathrm{MgO})$ has a higher flashover voltage than the conventional polyethylene (PE).

\section{ACKNOWLEDGMENTS}

The samples mentioned in the present paper were built by Prof. Yi Yin's research group at the State Energy Smart Grid R\&D Research Center, Shanghai, People's Republic of China.

\section{REFERENCES}

[1] G. Chen, M. Hao, Z. Xu, A. Vaughan, J. Cao, H. Wang, 'Review of high voltage direct current cables", CSEE Journal of Power and Energy Systems, Vol. 1, No. 2, pp. 9-21, 2015

[2] M. G. Danikas, R. Sarathi, P. Ramnalis, S. L. Nalmpantis, "Analysis of polymer surface modifications due to discharges initiated by water droplets under high electric fields", World Academy of Science, Engineering and Technology, Vol. 38, pp. 905-910, 2009

[3] M. S. Naidu, V. Kamaraju, High voltage engineering, Eds. Tata McGraw-Hill Publishing Co. Ltd., New Delhi, 2000

[4] H. -J. Kloes, D. Koenig, M. G. Danikas, "Electrical surface discharges on wet polymer surfaces", Proceedings of the $8^{\text {th }}$ International Symposium of Gaseous Dielectrics, Virginia Beach, Virginia, USA, pp. 489-495, June 1998

[5] K. Karakoulidis, M. G. Danikas, P. Rakitzis, "Deterioration phenomena on insulating surfaces due to water droplets", Journal of Electrical Engineering, Vol. 56, pp. 169-175, 2005

[6] M. G. Danikas, P. Rakitzis, K. Karakoulidis, "Study of parameters related to deterioration phenomena due to water droplets on polymeric surfaces", Journal of Electrical Engineering, Vol. 57, No. 3, pp. 130137,2006
[7] M. G. Danikas, R. Sarathi, P. Ramnalis, S. L. Nalmpantis, "Analysis of polymer surface modifications due to discharges initiated by water droplets under high electric fields", Int. J. Electr. Power and Energy Syst. Eng., Vol. 3, No. 1, pp. 19-24, 2010

[8] W. T. Starr, "Polymeric outdoor insulation", IEEE Transactions on Electrical Insulation, Vol. 25, No. 1, pp. 125-136, 1990

[9] A. E. Vlastos, S. M. Gubanski, "Surface structural changes of naturally aged silicone and EPDM composite insulators", IEEE Transactions on Power Delivery, Vol. 6, No. 2, pp. 888-900, 1991

[10] M. G. Danikas, "Polymer outdoor insulators", Acta Electrotehnica Napocensis, Vol. 40, No. 1, pp. 3-10, 1999

[11] M. G. Danikas, P. Ramnalis, R. Sarathi, "A study of the behaviour of water droplets on polymeric surfaces under the influence of electric fields in an inclined test arrangement", Journal of Electrical Engineering, Vol. 60, No. 2, pp. 94-99, 2009

[12] S. Feier-Iova, V. Hinrichsen, "Partial Discharge Inception Voltage of Water Drops on Insulating Surfaces Stressed by Electrical Field", International Symposium on High Voltage Engineering, pp. 21-25, 2009

[13] M. Kozako, R. Kido, N. Fuse, Y. Ohki, T. Okamoto, "Difference in surface degradation due to partial discharges between polyamide nanocomposite and microcomposite", IEEE Annual Report of Conference on Electrical Insulation and Dielectric Phenomena, pp. 398401, 2004

[14] M. Kozako, R. Kido, T. Imai, T. Ozaki, T. Shimizu, T. Tanaka, "Surface Roughness Change of Epoxy/TiO2 Nanocomposites due to Partial Discharges", Proceedings of 2005 International Symposium on Electrical insulating Materials, pp. 661-664, Japan, 2005

[15] J. K. Nelson, Dielectric polymer nanocomposites, Eds. Springer, Heidelberg, Germany, 2010

[16] I. Plesa, P. V. Notingher, S. Schloegl, C. Sumereder, M. Muhr, "Properties of polymer composites used in high-voltage applications", Polymers, Vol. 8, 2016

[17] H. Schnablegger, Y. Singh, The SAXS Guide. Getting acquainted with the principles, Anton Paar GmbH, 2011

[18] M. Jarvid, A. Johansson, R. Kroon, J. M. Bjuggren, H. Wutzel, V. Englund, S. Gubanski, M. R. Andersson, C. Müller, "A New Application Area for Fullerenes: Voltage Stabilizers for Power Cable Insulation," Advanced Materials, Vol. 27, No. 5, pp. 897-902, 2015

[19] L. A. Utracki, "Clay-containing polymeric nanocomposites and their properties", IEEE Electrical Insulation Magazine, Vol. 26, No. 4, pp. 615,2010

[20] E. David, M. Frechette, "Polymer nanocomposites - Major conclusions and achievements reached so far", IEEE Electrical Insulation Magazine, Vol. 29, No. 6, pp. 29-36, 2013

[21] E. A. Cherney, "Nanodielectrics applications-Today and tomorrow", IEEE Electrical Insulation Magazine, Vol. 29, No. 6, pp. 59-65, 2013 